\title{
Considerações sobre a fotografia Fine Art
}

\section{Considerations over Fine Art Photography}

\section{Filipe Mattos de Salles}

Universidade Estadual de Campinas

\section{Resumo}

O termo Fine Art é uma designação relativamente recente no Brasil, para abarcar especificamente a produção de imagens fotográficas com intenções puramente estéticas, não comerciais, em diferentes estilos, mercados e nomenclaturas. Com isso, o termo começou a ser amplamente utilizado até em ambientes comerciais, causando certa confusão com a definição de seus limites, sobrepondo o conceito do que era antes considerado, genericamente, fotografia artística. Por este motivo, cabe uma análise mais profunda sobre os termos em questão, no objetivo de conceituar corretamente o papel da fotografia enquanto manifestação artística e suas possibilidades de veiculação.

Palavras-chave: Fotografia; Fotografia artística; Fine Art; Fotografia analógica.

\begin{abstract}
The term "Fine Art" is a recent designation in Brazil to refer about artistic and noncommercial photography, in its different ways of expression. With it, the term caused some confusion on being used in both commercial and artistic views, overlaping the concept of general artistic photography. Because it, it's necessary a deep analysis about those terms to concept correctly what is the photography on its artistics aspirations.
\end{abstract}

Keywords: Photography; Artistic Photography; Fine Art; Analogic Photography. 


\section{Artigos e Ensaios na atualidade: relações praticadas}
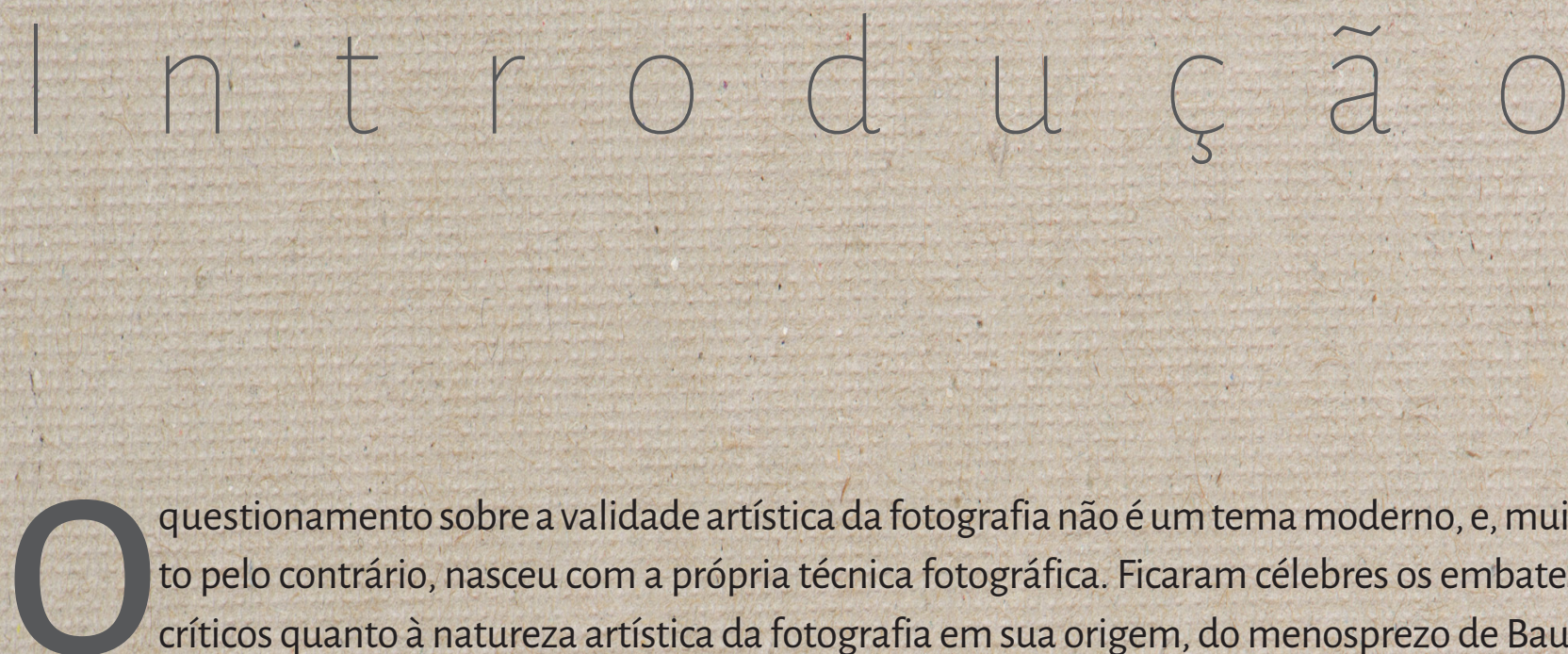

questionamento sobre a validade artística da fotografia não é um tema moderno, e, muito pelo contrário, nasceu com a própria técnica fotográfica. Ficaram célebres os embates críticos quanto à natureza artística da fotografia em sua origem, do menosprezo de Baudelaire e de Rodin às tentativas de defesa de Disdéri, Delacroix ou Degas (apud FERNANDES JR., 2002). É senso comum que a crítica considera hoje este pormenor resolvido, mas não por um argumento propriamente artístico, que se justifica no contexto da filosofia da arte, e sim pela persuasão da própria realização fotográfica, que foi aos poucos, e de forma desordenada, ocupando espaços artísticos até sua plena consolidação. André Rouillé (2009, p. 15), por exemplo, cita que a "legitimidade artística e cultural da fotografia é recente", atribuindo mudanças de paradigma neste sentido apenas a partir dos anos 1970, em que um grande número de exposições, mostras, escolas especializadas e publicações diversas colocaram a fotografia num patamar diferente do que vinha sendo praticado anteriormente. Masé ainda uma análise parcial, uma vez que as sociedades fotográficas, foto clubes e mesmo galerias especializadas remontam ao final do século XIX, conforme atesta Sougez (2001), ou nas considerações de Sullivan e Weese (1998, p. 8), em que a fotografia, para ser considerada 'artística' pela crítica especializada do final dos anos 1880 , deveria ter seu negativo revelado em ácido pirogálico e copiado em papel de platina, o Platinotype, para que a gama exuberante de contrastes obtida por este processo pudesse corresponder aos anseios estéticos de então. Isso sem falar da própria denominação de fotografia 'pictórica' (chamado atualmente de pictorialismo), por H. Peach Robinson em 1869 (SOUCEZ, 2001)'. Todas estas considerações apontam para o fato inegável de que sempre houve, quer documentadas oú não, intenções estéticas profundas no fazer fotográfico, e a pouca literatura que se ocupa desta perspectiva acaba por deixar dúbias certas afirmações. Faltam, portanto, soluções mais efetivas na área da arte e da imagem que permitam estabelecer parâmetros mais precisos para o entendimento destes fenômenos, uma vez que nem uma definição formal da fotografia é consensual entre os autores.

Esta é a razão que justifica tecer ligações objetivas entre a filosofia platônica (como suporte de uma estética baseada num critériọ ideal) e a psicologia junguiana (como base para o entendi-

1 Segundo Sougez (2001), diversos grupos e sociedades fotográficas surgiram entre 1890 e 1900 promovendo exposições, mostras e publicações sobre fotografia tendo' como principal interesse responder positivamente a um questionamento do crítico Robert Szireranne: "Fotografia é arte?". 
mento da necessidade em tornar este ideal concreto, e de que forma ele afeta nossa vida psíquica), e assim, baseado em meu trabalho anterior (SALLES, 2016), conseguir entender plenamente o fenômeno estético, e em consequência, o fotográfico em sua dimensão artística.

\section{A natureza da fotografia}

De um ponto de vista mecanicista, a fotografia pode ser definida como o registro de uma imagem diretamente pela luz, podendo esta, por sua vez, ser atra-

De um ponto de vista mecanicista, a fotografia pode ser definida como o registro de uma imagem diretamente pela luz, podendo esta, por sua vez, ser através de uma ordenação de seus raios (com uma objetiva ou furo), ou ainda por contato e projeção. vés de uma ordenação de seus raios (com uma objetiva ou furo), ou ainda por contato e projeção. Podemos compará-la, para fins de melhorilustrar sua natureza, a outros registros, como o sonoro, por exemplo. Uma gravação sonora nada mais é que uma "fotografia" de sons, só que disposta no tempo, como o cinema. O microfone é um equipamento similar à lente, ou à objetiva, e o gravador equivale à câmara escura e ao suporte fotossensível, onde é feito o registro, tanto analógico como digital ${ }^{2}$.

Entretanto, o fenômeno fotográfico é bem mais complexo, pois adquire significado além de seu próprio processo. De um ponto de vista estético, talvez faça pouco sentido apreciar uma "gravação" em si, em detrimento do conteúdo, que seria, no caso de uma música, a obra gravada. Mas na fotografia, o registro em si (o ato fotográfico) pode ser digno de apreciação, independente do assunto fotografado, como propõe, notoriamente, Dubois (1993). Por este motivo, a fotografia situa-se numa encruzilhada de sentidos extremamente interessante para nossa percepção: como registro mecânico, comporta-se como o som, mas como resultado, é visual: comporta-se como arte pictórica. Disso resulta toda a sorte de possibilidades de interpretações, e que causam certa confusão até mesmo nos pensadores mais rigorosos, que por vezes tratam a fotografia com relação ao seu referente ${ }^{3}$. (ou o conteúdo da fotografia, como a música gravada), por vezes mesclam com sua técnica intrínseca, (ou a fotografia como obje-

2 A única diferença mecânica é que não faz sentido "congelar" um som, pois ele é inteligível a partir de uma percepção cronológica, estando, pois, subordinado ao eixo temporal, ao passo que a fotografia tem justamente como virtude a possibilidade de congelar um instante de luz.

3 André Rouillé $(2009$, p.70) considera este aspecto de maneira enfática, nominando um de seus subtítulos de "o Culto do Referente". 
to, no jargão semiótico, o que seria equivalente a apreciar a técnica utilizada para a gravação, além de seu significado), e ainda outras vezes não definem claramente de qual aspecto estão se referindo, tentando abranger uma quase infinita gama de possibilidades interpretativas, o que, considerando a subjetividade da interpretação pessoal, é uma tarefa hercúlea e, inexoravelmente, incompleta. Daí a existência de certos paradoxos na interpretação do fenômeno fotográfico, principalmente no âmbito da semiótica, que procura justamente entender as relações de significado essenciais ao objeto, conforme já atestaram referências como Arlindo Machado (2000) e Rubens Fernandes Jr. (2002).

E, no meio desta vasta seara, um aspecto desponta, no sentido de unificar todas as tendências possíveis de interpretação da imagem fotográfica: sua estética, ou, antes, seu potencial artístico. Excetuando-se a fotografia amadora, cujo potencial emotivo sobressai ao aspecto estético, tornando-se artística pela beleza da evocação mnemônica, todos os demais gêneros fotográficos, comerciais ou não, tem, de maneira explícita ou implícita, uma intenção última de se projetarem como imagens emblemáticas, o que pressupõe a utilização de padrões estéticos na sua construção. Em palavras mais simples, todas as imagens fotográficas almejam o status de imagem artística.

Mas o que é uma imagem artística? A partir desta premissa, a problemática da avaliação da imagem fotográfica começa justamente em reconhecer parâmetros que permitam classifica-la numa escala estética de valores, que se mostra menos intuitiva que outros exemplos de artes visuais, porque a imagem fotográfica figurativa é construída diretamente pela objetiva, sendo possível que até mesmo fotógrafos amadores ou sem intenções estéticas deliberadas alcancem resultados artísticos, ainda que isolados.

A título de exemplo, a fotografia brasileira persiste numa valorização acentuada do gênero tipicamente fotojornalista, em detrimento de outros gêneros pouco cultivados aqui, como o pictorialismo, a fotografia abstrata ou a de grafismo. Assim, os valores artísticos, ainda que subjetivos e construídos artificialmente, são desiguais entre os diversos gêneros, de sorte que há um fetichismo (no sentido adorniano) para a imagem de um Cartier-Bresson e não para a de um Ansel Adams ${ }^{4}$, sendo que não são valores estabelecidos pela imagem em si, e sim por um modismo padronizado de preferencia entre gêneros. Esta subjetividade se mostra então vinculada a um modelo estético estabelecido nas críticas, nas curadorias e nos meios de comunicação, forçosamente unilateral, e que impede uma visão mais amplá que permitiria uma consciência artística livre de padrões comuns.

4 Do ponto de vista meramente histórico, o Grupo f/64, do qual Adams fazia parte, se colocou esteticamente em oposição à tradição pictorialista de então. Entretanto, em meu trabalho anterior (SALLES, 2016), utilizo uma acepção mais abrangente do termo 'pictorialismo', e é esta a que me refiro aqui. 
Outro problema é a própria nomenclatura que distingue a fotografia não comercial, para fins exclusivamente artísticos, que seria, em termos genéricos, a chamada fotografia Fine Art. O grau de subjetividade que se pode imprimir a este gênero é tal que uma foto pode ser assim considerada apenas pelo método de acabamento, que implica tratamento da imagem em alta resolução e processos de impressão gráfica de alta qualidade. A revista brasileira FHOX, especializada no mercado fotográfico comercial, publicou na edição 162 de 2013, um encarte especificamente sobre Fine Art na intenção de apresentar o potencial de comercialização do gênero no Brasil, e contou com depoimentos de três fotógrafos de notório reconhecimento, Cristiano Mascaro, Clicio Barroso e Eder Chiodetto. Cada um à sua maneira, expuseram sua visão sobre o que é o Fine Art, com algumas diferenças de discurso: Chiodetto cita apenas a questão da reprodução fotográfica, a chamada impressão Fine Art, como sendo o parâmetro fundamental para classificação da imagem fotográfica nesta categoria, enquanto os demais, em diferentes graus, atribuem este rótulo também ao critério de conteúdo, dividindo assim o peso da nomenclatura entre a proposição estética e a impressão finalizada. Muitos estúdios comerciais apresentam a seus clientes, por conta desta característica, a opção de realizar um ensaio em Fine Art. É notório, apenas por este encarte, que num contexto geral não há uma distinção claramente estabelecida entre a fotografia Fine Art e a fotografia comercial, ou mesmo fotografia artística num âmbito genérico. Uma imagem que atenda a critérios mínimos de qualidade em aspectos técnicos fundamentais (enquadramento, composição de quadro, iluminação, exposição, postura e expressão dos modelos), pode ser considerada Fine Art se copiada em condições qualitativas que assim as caracterize, tornando o tipo de embrulho critério de qualidade do produto.

Acrescenta-se ainda um fenômeno curioso que recentemente tem tomado conta do mercado fotográfico deixando empresas, comerciantes e fotógrafos desnorteados: A fotografia se digitalizou na mesma proporção em que as tecnologias evoluíram para iṃagens com maior qualidade, e assim também, na mesma razão, houve um acréscimo de ferramentas mais simples e acessíveis para manipulação e tratamento eletrônicos. Entretanto, grupos entusiastas da arte fotográfica têm insistido em utilizar suporte analógico para gerar matrizes originais em fotografia, independentemente do fato de produzirem cópias também analógicas ou através da digitalização por scaner destes originais, que em geral são negativos fotográficos. Este fenômeno pode ser percebido em inúmeros artigos de representantes destes grupos, que não apenas defendem que certas abordagens artísticas só podem ser plenamente realizadas através do filme, como prestam auxílio para jovens fotógrafos tentarem por si mesmos realizações analógicas nos tempos atuais, em que cada vez mais os laboratórios analógicos se tornam peças de museu e seus equipamentos se convertem em raridades históricas. Citamos exemplos de textos nos blogs de Angie Kordic (2015), Matthias Hombauer e Karl Blümel (2013), além de 
Artigos e Ensaios

Fotografia, Arte e História

na atualidade: relações praticadas

revistas virtuais independentes, que divulgam trabalhos exclusivamente feitos em filme, como a BLUR Magazine (2016), Girls on Film Zine (2011), Soabos Magazine (2015) e al gumas comunidades virtuais (blogs) especializadas em formatos específicos de filmes analógicos raros, como 0727 Film Photography (2017), View Camera (2010) e Large Format Photography (1995), sem contar as lis-' tas de discussão. É notório que quase todas as revistas especializadas em fotografia, mesmo as que não se dedicam exclusivamente à fotografia analógica, quer em edições impressas, quer em versão digital, em algum momento privilegiam ou destacam fotógrafos analógicos e trabalhos feitos em filme, como a eminente revista The British Journal of Photography.

Em função desta grande quantidade de comunidades interessadas no potencial expressivo do filme, cabe perguntarmo-nos qual a razão de tal fenomenologia, considerando que nossa sociedade de imagens já vive inserida numa realidade digital, e é plenamente reconhecida a possibilidade do suporte digital se igualar, na maioria das saídas impressas disponíveis no mercado, o suporte analógico. Diferentes pontos-de-vista podem ser elencados em função das atividades de cada comunidade dedicada ao filme, e que poderíamos resumir em alguns fatores: o modismo arraigado na tradição fotográfica que se perpetua, tal como um espectro fantasma, de um pensamento analógico repetido à exaustão ${ }^{5}$; ou uma questão real de qualidade discreta que o suporte digital em proporções específicas não alcançaria, em relação à textura, cor ou profundidade; um aspecto plenamente justificável de sublimação psicológica de um complexo de inferioridade, uma vez que a fotografia digital permite o uso desenfreado do modo automático, e o fotógrafo que se aventure pelo analógico em nossos dias possui o natural estigma de saber realmente fotografar; ou então uma variação do aspecto anterior, que seria o fato de que o trabalho manual e artesanal da fotografia analógica imprima não apenas uma sensação de seriedade ao trabalho, mas efetivamente um comprometimento maior com a proposta estética. Temos razões para crer que, em virtude da diversidade de públicos interessados no assunto, uma confluência genérica de cada um destes fatores pode ser determinante para explicar tal comportamento.

Estas questões levantadas sobre este film revival, permitem deduzir que há uma necessidade estética inerente ao fazer fotográfico e que se torna, por esta razão, uma questão crucial no entendimento do fenômeno fotográfico. Não se trata apenas entender a necessidade de sobrevivência do filme fotográfico, mas também refletir sobre a questão do suporte como elemento relevante para realização expressiva no campo da arte. Em outra palavras, entenderíamos como a escolha do filme em lugar do sensor digital pode contribuir para viabilizar certas concepções estéticas da imagem, ou que tipo de diferenciação o filme pode proporcionar não apenas no que diz respeito ao resultado artístico, mas também no processo criativo, dado que seu modo de operação pres-

5 Mas neste caso, como a simples inércia que justifica a tendência em manter a tradição analógica poderia explicar o entusiasmo de jovens fotógrafos que nasceram na era digital e não conviveram com o filme? Claramente há outros fatores em jogo, que adiante elucidaremos.

64

Resgate-Rev. Interdiscip. Cult., Campinas, v. 26, n. 2 [36], p. 59-78, jul./dez. 2018 -e-ISSN: 2178-3284 
supõe a pré-visualização mental, conforme descrita por Ansel Adams (1997), inerente ao fato de não ser possível a visualização imediata do resultado. Frente a estes aspectos, Fontcuberta ( 2010 , p. 189) levanta a tese de que a fotografia digital se apresenta como um fenômeno diferente da fotografia analógica, que o levou a propor uma era pós-fotográfica, em que "a fotografia digital' se escreve, em oposição à fotografia química, que se inscreve". Seria este fator verificável na realização prática da fotografia artística?

Meu trabalho anterior (SALLES, 2016) propõe, por outro lado, que a fotografia, como materialização de um ideal, independe de seu suporte, e a viabilização de um ou outro processo só estabelece relação de dependência com a ideia-matriz que gerou a necessidade estética, sendo, portanto, a forma uma mera decorrência da tradução sensível desta matriz (PLATÃO, 1999). Por este viés, fica claro que a opção por um determinado suporte depende de uma ideia prévia, e não que a estética seja determinada pelo suporte. Esta visão permite, ainda, conjecturar a subjetividade do julgamento artístico num plano mais sólido e abrangente, tratando cientificamente algo que não teria, naturalmente, esta vocação.

Esta é uma questão fundamental, afinando-se com a discussão contemporânea sobre a inserção da tecnologia no processo criativo artístico, e, neste contexto, como a fotografia reage a todo este movimento.

Todas estas indagações, que podem ser resumidas no problema de definir (ou pelo menos conceituar) o que é a arte, a fotografia, e, consequentemente, o que é a fotografia artística e qual seu papel na elaboração de conteúdos visuais significativos no contex to de uma sociedade imersa em imagens, se tornam necessárias e imprescindíveis para a compreensão dos fenômenos estéticos segundo uma perspectiva de pensamento moderna, e que este trabalho visa contemplar através de um ponto de vista menos mecanicista que energético ${ }^{6}$, e, antes de tudo, deveras filosófico.

\section{O conceito de arte}

Poucos temas na história da literatura crítica, científica ou ensaística são mais complexos e vagos que a definição da arte. É um assunto debatido a graus extremos de exaustão (a julgar pela quantidade de páginas escritas sobre isso), sem que se possa chegar a um consenso ou a uma definição precisa sobre o que é arte. O problema é tão profundo que mesmo Ernest Combrich

6 Esta dicotomia é mencionada em Jung (1999, p. 3): "É fato universalmente conhecido que os fenômenos físicos podem ser considerados sob dois pontos de vista distintos, a saber: do ponto de vista mecanicista e do ponto de vista energético". 
(2009, p. 15), autor de uma das mais populares histórias da arte de nossa literatura, foi taxativo: "Nada existe realmente a que se possa dar o nome de Arte. Existem somente artistas", e, ainda, Richard Salkeld (2014, p. 152) chegou a mencionar enfaticamente que "nunca se chegará a uma unanimidade a esse respeito".

No entanto, temos que partir de algum pressuposto, sem o qual não é possível construir as bases necessárias para uma reflexão que se queira coerente e cientificamente válida. Para fins práticos, adotaremos aqui o conceito sugerido em meu trabalho anterior (SALLES, 2016), na qual a arte é vista como uma resultante sensível da mediação entre um objeto e um modelo ideal, que é dado previamente numa instância pessoal de interpretação, segundo seu alcance sensível. Este conceito recorre à noção platônica de que existe um modelo ideal inteligível de todas as formas existentes na terceira dimensão (mundo sensível), e assim, frente a um objeto qualquer, é estabelecida uma comparação, absolutamente individual e, no mais das vezes, deveras inconsciente, entre o modelo e o objeto, sendo que, ainda utilizando a nomenclatura platônica, o distintivo entre os objetos que permitem estabelecer uma sensação artística (a que chamamos de estética) estão nos critérios de ideal bom, belo e grande (ou verdadeiro), ou seja, nos graus de aproximação que o objeto estabelece com estes elementos, segundo tais critérios (PLATÃO, 1999). Será arte aquilo que encontra ressonância com tais ideais profundamente enraizados na psique dos indivíduos.

Portanto, a arte é um conceito relativo: será arte para alguém o objeto ou ação que representar uma tradução de um ideal, e tanto mais arte quanto mais este ideal for, para este indivíduo, uma representação daquilo que, para ele, é bom, em diferentes graus segundo o seu entendimento pessoal. Disso decorre: a) qualquer coisa pode ser arte, pois a arte não está no objeto, e sim na mediação entre ideal representado e indivíduo. Daí a apropriação do termo para designar, por exemplo, futebol-arte ou arte gastronômica; b) há artes com potencial de alcance mais abrangentes que outras, dado o aspecto da energia do arquétipo (e neste ponto nos auxilia toda a conceituação junguiana) que certas ideias possuem, e, portanto, um consenso sobre certos objetos serem, efetivamente, arte, enquanto outros geram controvérsia. Isso explica o alcance da arte de um Shakespeare, de um Mozart ou de um Leonardo. Mas mesmo estas figuras não estão isentas de julgamentos contrários, uma vez que um indivíduo pode não encontrar ressonância com suas obras; c) um objeto artístico é mutável: frente a uma mudança de paradigmas nos ideais de um indivíduo, ou mesmo a partir de uma conscientização maior sobre aspectos de sua própria psique, algo que ele não considerava arte, passa a considerar, e vice-versa. Por isso Schiller (1991a) nos fala de uma "educação estética"; d) a competência técnica de um artista é decisiva, pois do pleno domínio de um determinado suporte, é que a tradução do ideal torna-se mais clara, harmônica e objetiva, tornando seu objeto artístico mais estético e abrangente. É a razão pela qual muitos matemáticos dizem que há formas mais "elegantes" de se demonstrar um teorema. 
Ora, que diferença faria uma solução de outra se ambas chegam ao mesmo resultado? Por isso a arte e a estética são realidades que, conscientes ou não, norteiam nossas escolhas. E, por fim, e) esta abordagem explica de uma forma muito mais lógica a não existência de uma "evolução" cronológica na arte, na mesma medida em que se pode falar de uma evolução tecnológica. É possível falar de evolução da obra de um artista, porque ele refinou seu estilo na busca por uma representação cada vez mais objetiva e elegante de seu ideal de belo, mas não é possível falar que determinada arte é melhor que outra em termos cronológicos, justamente porque se trata de uma tradução de um ideal, e, sendo o ideal imutável, o que muda é sua representação. Na mesma razão está o fato de que provavelmente o que motivou as primeiras manifestações artísticas não foram estímulos externos, ligados aos assuntos retratados, mas sim a essa busca pelo ideal, inerente à natureza humana, ainda que de forma inconsciente.

É oportuno mencionar que este conceito platônico encontra ecos mais modernos principalmente na filosofia estética de Hegel (2009), Croce (2016) e Schiller (1991a e 1991b), e, em alguma medida, também em Arnheim (1986) e Tolstói (2016), e foi adotado por sua inequívoca maior abrangência às demais tentativas de definir ou conceituar a arte, na medida em que não conseguem tratar de maneira plena e satisfatória da singular característica da subjetividade artística, que é a interpretação do belo em cada indivíduo. As variáveis são numerosas, de argumentos mais próximos de uma conceituação sociológica e política, passando pelo elogio à tecnocracia, à pura lógica de mercado, mas sempre tendo que justificar de forma dissimulada idiossincrasias diametralmente opostas, como a Pietà de Michelangelo à Fonte de Duchamp, no mesmo paradigma da arte.

A vantagem de abordar este conceito pela ideia é que estamos numa instância anterior ao objeto artístico em si e, portanto, no mundo em que estes objetos são efetivamente criados, suas ideias, e assim, não corremos o risco de cair na tentação de analisar a arte pelos seus objetos, que é, conforme constatamos, infrutífero, dada a natureza ilusória deles. Assim, considerando as variáveis de interpretação pessoal (a representação do ideal de bom, belo e verdadeiro para cadá indivíduo), é possível abarcar a natureza artística tanto da Pietà quanto do urinol.

\section{A arte fotográfica}

Frente estas considerações, observamos a elementar conclusão de que sob o contexto da potencialidade estética, a fotografia não se diferencia de nenhum outro suporte de expressão, possuindo igualmente vocação para ser arte, dadas as mesmas variáveis. No entanto, ela conta 
com uma diferença fundamental intrínseca em sua natureza, que é a apreensão de uma imagem diretamente pela ação da luz, num mecanismo similar ao que nosso olho promove. Apesar de parecer um mero capricho formal, ou uma circunstância irrelevante, é deste pormenor que se originaram todas as controvérsias acerç da fotografia em relação à pintura, e é deste aspecto que quase todos os teóricos específicos da fotografia (por exemplo, Soulages, Benjamin, Barthes, Sontag, Flusser, Dubois, Machado ou Rouillé), vão se reportar na tentativa de compreender o fenômeno fotográfico. O fato de a fotografia imprimir numa fração de segundo uma emanação de luz, reproduzindo imagens que se assemelham às coisas que vemos com os olhos (dado que os princípios físicos do olho e da objetiva são os mesmos), nos causa mais do que uma sensação, nos fornece uma ilusória certeza absoluta de que aquele fato realmente existiu tal qual foi capturado. A consequência direta deste engano fundamental é que muitos autores, durante toda a história da fotografia, não conseguiram separar o olho do espírito: o que vemos mecanicamente nos fornece uma imagem, mas sua interpretação não é propriedade do aparelho ocular, e sim da psique, sendo da mesma forma com a câmera. Flusser (1985), por exemplo, tece toda uma estrutura de pensamento baseado no funcionamento mecânico da câmera, e não na construção da imagem pelo fotógrafo. Salkeld (2014, p.148) cita que o filósofo inglês Roger Scruton "defendeu veementemente que a fotografia não pode ser arte", porque "a câmera não tem imaginação", e "só é capaz de mostrar o que está à sua frente e o que existe".

Não são poucas as críticas modernas a este pressuposto, das quais já discuti em profundidade no meu citado trabalho anterior (SALLES, 2016), mas o fator inercial que muitos anos de análise segundo esta razão nos relegaram fornece parâmetros para reflexões ainda hoje. É preciso estabelecer de forma categórica que esta premissa é falsa, e lembrar que a fotografia, qualquer que seja sua intenção ou resultado, é sempre uma interpretação, sendo, no mínimo, um ponto-de-vista que o fotógrafo escolheu entre infinitos outros.

Mas tal fato, em si mesmo, também não confere automaticamente à fotografia um caráter artístico, apenas (e condicionalmente) de forma potencial. Por este motivo existe um gênero fotográfico conhecido, de forma bastante abrangente, como fotografia amadora. Este tipo de fotografia merece uma análise na medida em que, diferentemente de outras artes, existe uma facilitação através da tecnologia de auto ajuste de uma câmera, e permite que, teoricamente, qualquer pessoa realize uma fotografia de qualidade técnica perfeita, mesmo sem dominar o suporte. $\mathrm{Na}$ pintura, escultura ou outros suportes em que o aparelho é o corpo do artista, uma diferença de competência técnica é muito mais evidente, e dificulta ao artista se esquivar por algum mecanismo automático. Apesar deste fato representar a origem da maioria das críticas à arte fotográfica mencionadas anteriormente (desde, pelo menos, a industrialização da câmera por George Eastman, em 1888), na verdade esta facilidade tecnológica apenas relega à fotografia seu caráter comerciál entre amadores, pois a diferença entre um registro amador e um profissional reside exa- 
tamente na intenção estética: ao amador basta cumprir a função mnemônica em que a imagem estabelece a conexão com o emocional, relativo a cada situação, enquanto que ao profissional, interessa a busca por uma imagem arquetípica, absoluta, que traduza da forma mais profunda e abrangente possível, uma ideia pura: eis a arte.

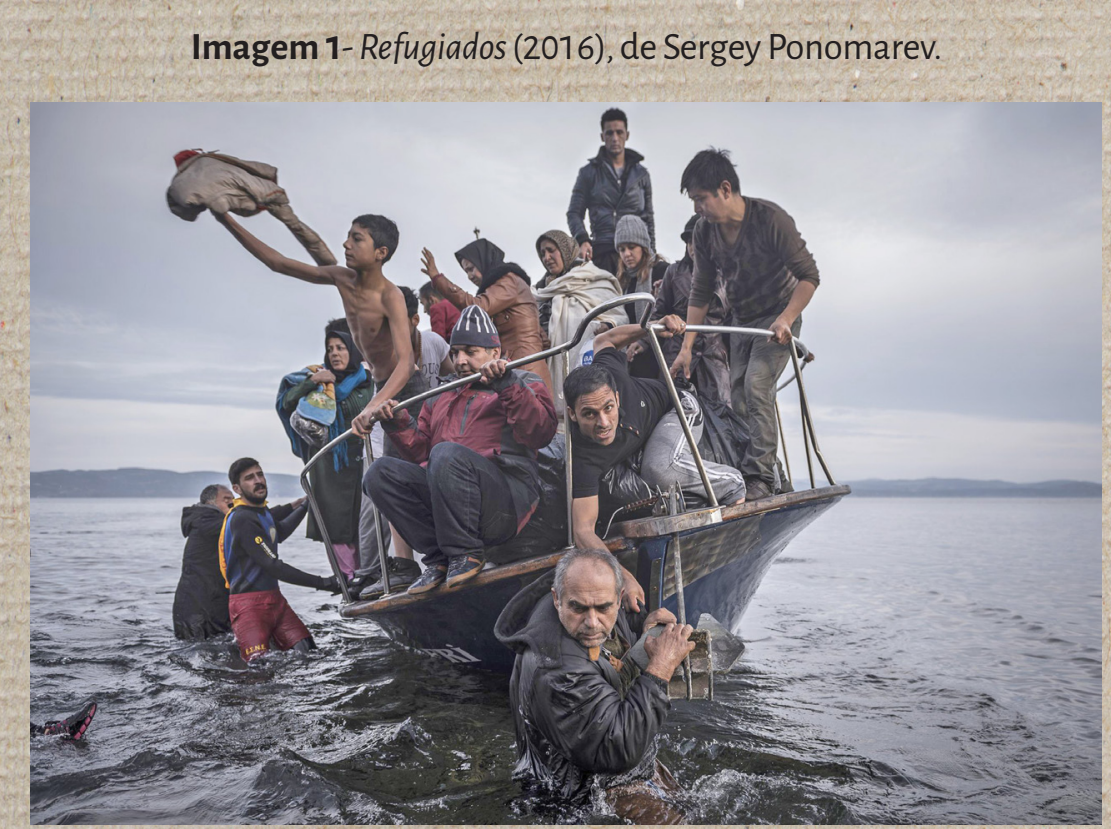

Fonte: New York Times (2016).

Imagem 2 - A balsa de medusa (1818-19), de Théodore Céricault.

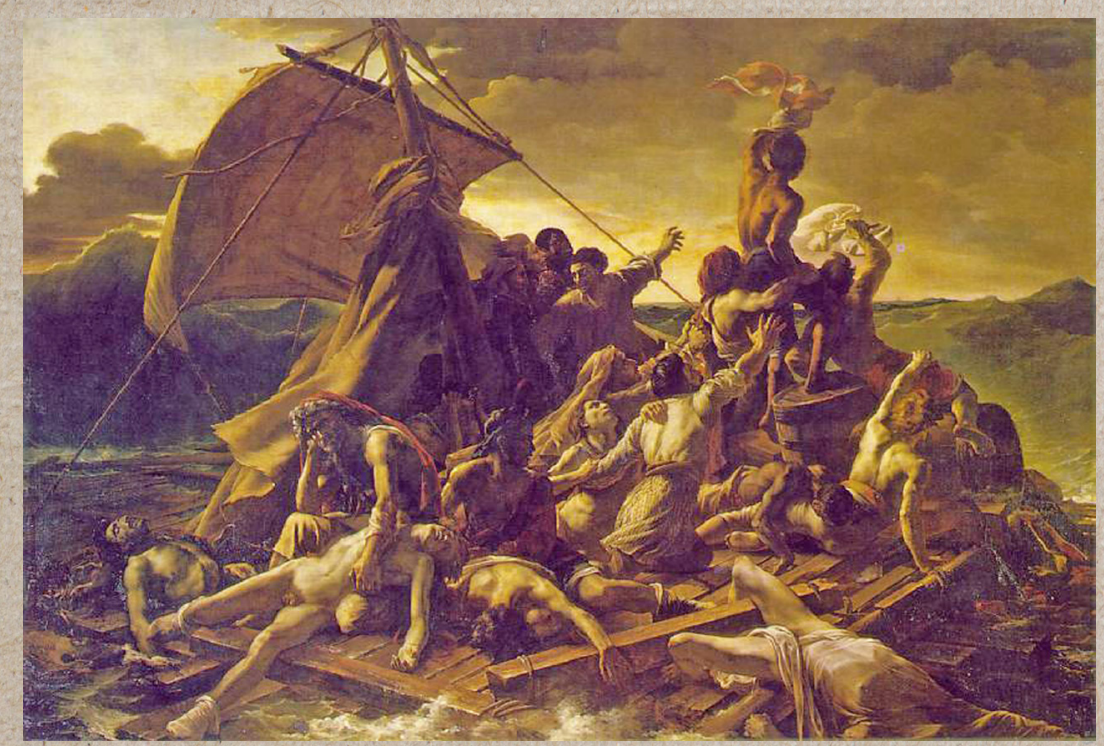

Fonte: Artsy.net (2017).

Este exemplo acima serve também, além da evidente comparação artística, para ilustrar que este potencial estético desejável na fotografia profissional não é restrito a uma imagem construída em estúdio, ou mesmo a uma paisagem pictorialista, mas que está presente em qual- 


\section{Artigos e Ensaios na atualidade: relaçôes praticadas}

quer manifestação que se queira, justamente por isso, profissional. Até mesmo o fotojornalismo, que conta com fatores ocasionais que não podem ser previstos diretamente, não prescinde de uma necessidade formal característica da construção estética da imagem, como equilíbrio e harmonia (conforme amplamente descrito por Arnheim, Croce e Tolstói em suas teorias da arte). Eventuais cliques dados em momentos decisivos que não puderam contar com um primor de composição, são sumariamente editados na pós-produção, afim de requadrar a imagem para fins estéticos, prática essa que é muito anterior à edição digital, e também utilizada largamente mesmo na fotografia de estúdio:

Imagem 3: Stravinsky (1946), por Arnold Newman.

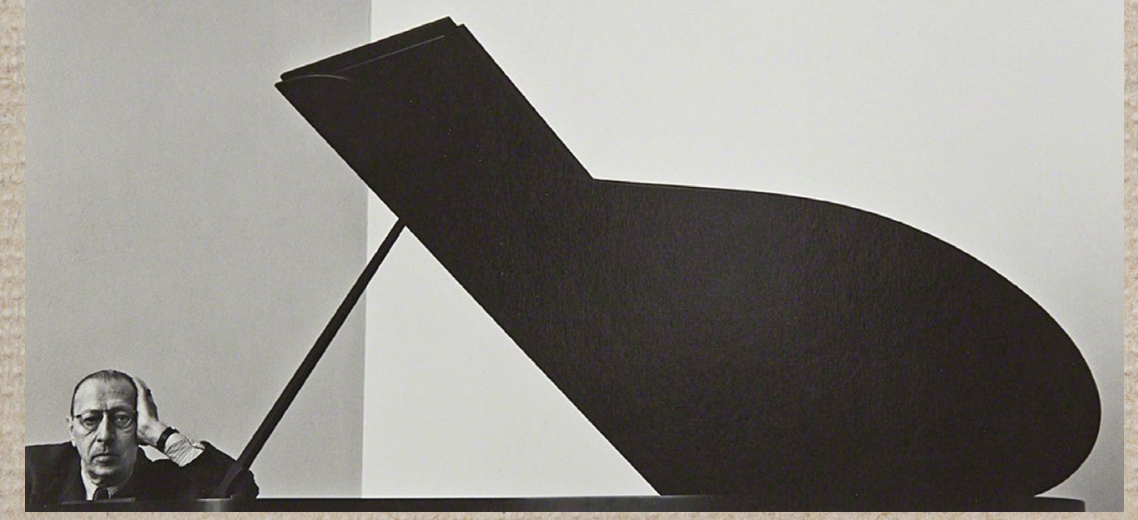

Fonte: Artsy.net (2017).

Imagem 4 - Stravinsky (Contato do negativo original, 1946), por Arnold Newman.

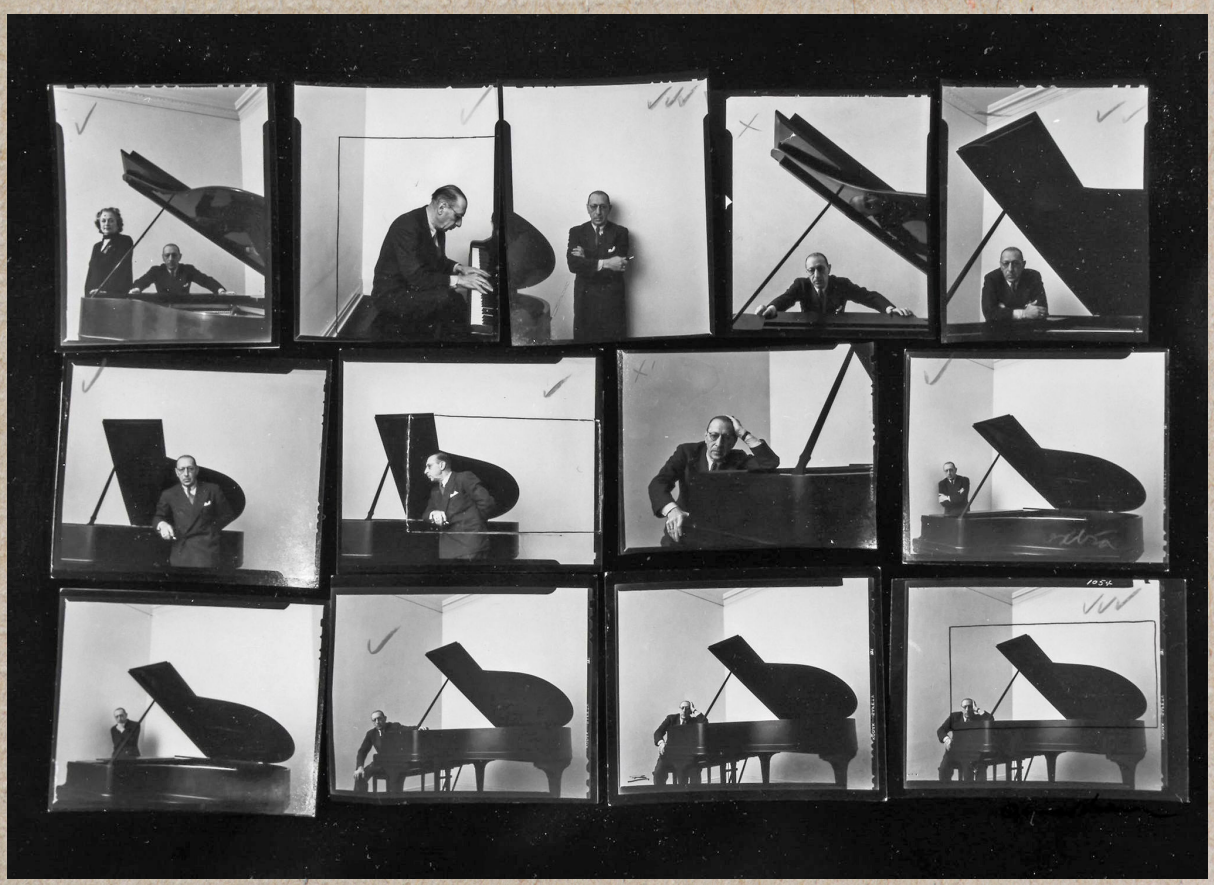

Fonte: Pixls.us (2016). 
Ora, como toda imagem profissional intenta alcançar a essência de sua ideia na forma, o arquétipo que a simboliza pode se revestir de infinitas variações que depreendem em si a energia emocional necessária para sua apreciação. Destarte, podemos considerar que a materialidade do produto final, e consequentemente, seu apelo estético, não dependem da variedade de métodos de obtenção da imagem, e sim da sua presentidade final. Assim, mesmo com um equipamento limitado em termos tecnológicos, se a imagem obtida manifestar consonância com o ideal da qual emerge sensivelmente, temos um potencial estético. Tal é que mesmo imagens amadoras estão sujeitas a este crivo, e pela mesma razão uma imagem feita numa tecnologia inferior não está sujeita à inferioridade artística.

Mas se a apresentação de uma imagem faz sua diferença, não poderia também a fotografia publicitária entrar no patamar de imagem artística? Visando, evidentemente, um fim mercadológico, a forma em que se apresenta é notoriamente programada friamente
Ora, como toda imagem profissional intenta alcançar a essência de sua ideia na forma, o arquétipo que a simboliza pode se revestir de infinitas variações que depreendem em si a energia emocional necessária para sua apreciação. Destarte, podemos considerar que a materialidade do produto final, e consequentemente, seu apelo estético, não dependem da variedade de métodos de obtenção da imagem, e sim da sua presentidade final. para ser atraente ao público a quem se destina, o que a torna uma mera repetição de modelos estéticos (ideias) preexistentes com o intuito de facilitar a compreensão de seu público, altamente variável. É a utilização de um código já consagrado, para que a mensagem seja entregue de forma a mais efetiva possível. Mas não está exatamente nestes aspectos formais sua eventual inferioridade estética, pois alguém que não compreenda os códigos estéticos ou mesmo comerciais de uma determinada sociedade pode, desavisadamente, atribuir uma emoção a uma imagem publicitária sem que este tenha laços com o produto em questão. O fator que nos impele a não vê-la com olhos puramente artísticos (o que não exclui a possibilidade de uma categorização específica: "este anúncio é tão bonito, uma verdadeira obra de arte!") é seu vínculo comercial, pois estabelece uma relação fria em que a ideia por trás da beleza estética é prisioneira da venda de um produto, e não uma ideia livre. Schiller (1991b, p. 70) já nos alertava que, "a arte criativa é inteiramente livre, porque afasta se seu objeto toda a limitação casual”, o que é exatamente o caso da publicidade. Não há razão, entretanto, para não se poder apreciar um trabalho publicitário e, em função de sua qualidade, categorizá-lo como "arte publicitária". 


\section{Artigos e Ensaios $\quad$ Fotografia, Arte e História \\ na atualidade: relações praticadas}

Um pouco diverso é o caso do fotojornalismo, que, por comercial que seja, tem em sua formação arquetípica o estigma (ilusório) de que a notícia é idônea e que, apesar da controvérsia sobre tal fato, "vende" mais um ponto de vista ideológico que um produto comercial. Além disso, quando o fotojornalismo envereda, como em grande parte dos casos, para denunciar injustiças e promover causas sociais (como a.Imagem 1 anterior), remonta a uma ideologia que parece simpática aos olhos de um público genérico; ràzão pela qual a empatia com ideais nobres torna a imagem emblemática em grau muito maior do que a imagem publicitária.

\section{Fotografia Artística e Fine Art}

Assim chegamos ao diferencial entre os tipos de fotografia não comercial, e que também exige certa explicação prévia: o fato de considerar uma fotografia não-comercial não significa, obviamente, que ela não pode ser comercializada; antes, quer apenas dizer que foi feita para expressar uma ideia pura, sem que exista necessariamente um produto do qual é referente-e que tem, em si, a ideia intrínseca de intenção comercial. Esta é a razão pela qual uma obra típica da Pop Art, como a série Campbell's Soup (1962) de Andy Warhol, pode ser apreciada como arte e não como propaganda. Ela é sobre um produto, mas a repetição ostensiva do motivo denota justamente a crítica à sociedade de consumo, traduzindo assim um ideal mais abrangente e profundo que o objeto em si: torna-se estético.

Num panorama geral, a imagem fotográfica construída a partir de uma necessidade expressiva pode ser considerada uma imagem com intenções artísticas, intenção esta que se efetiva condicionalmente, desde que, claro, preencha os requisitos formais que as tornem representações ideais, e assim genericamente falamos de uma "fotografia artística". A questão que se interpõe é que a apresentação de uma fotografia artística é extremamente variável e é possível identificar ou mesmo apreciar uma fotografia artística em seu estado bruto, como, por exemplo, num site, numa cópia gráfica impressa ou mesmo numa impressão interpolada e ampliada por retícula. Se pudermos expressar de maneira simples este conceito, seria, à revelia de uma teoria de marketing avançado, "a forma de expor um produto não fará diferença para a apreciação de seu conteúdo" . Por conta disso, é possível tomar contato com fotógrafos e efetivamente apreciar seus trabalhos através de publicações impressas, coisa que não faz sentido

7 Entretanto, a aplicação disso na prática é que uma imagem fotográfica ampliada e exposta num museu causa um impacto muito diferente da mesma obra apreciada num livro de artista. 
na qualidade da pintura ou da escultura. As publicações neste caso servem apenas para fins de catálogo e referência, pois é evidente que uma publicação não substitui a visita a um museu ou uma galeria. A fotografia é mais flexível neste quesito, pois até mesmo o tamanho de uma ampliação é variável e pode mudar dependendo do ambiente, da mostra e do orçamento. Cópias contato a partir de originais $8 \times 10^{\prime}$ podem ser impressos com al ta qualidade gráfica exatamente no tamanho do original, e, assim, apreciar o impresso tal qual uma cópia autêntica ${ }^{8}$, como neste exemplo de Josef Sudek:

Imagem 5-From the series the window of my studio (1950-1954), de Josef Sudek.

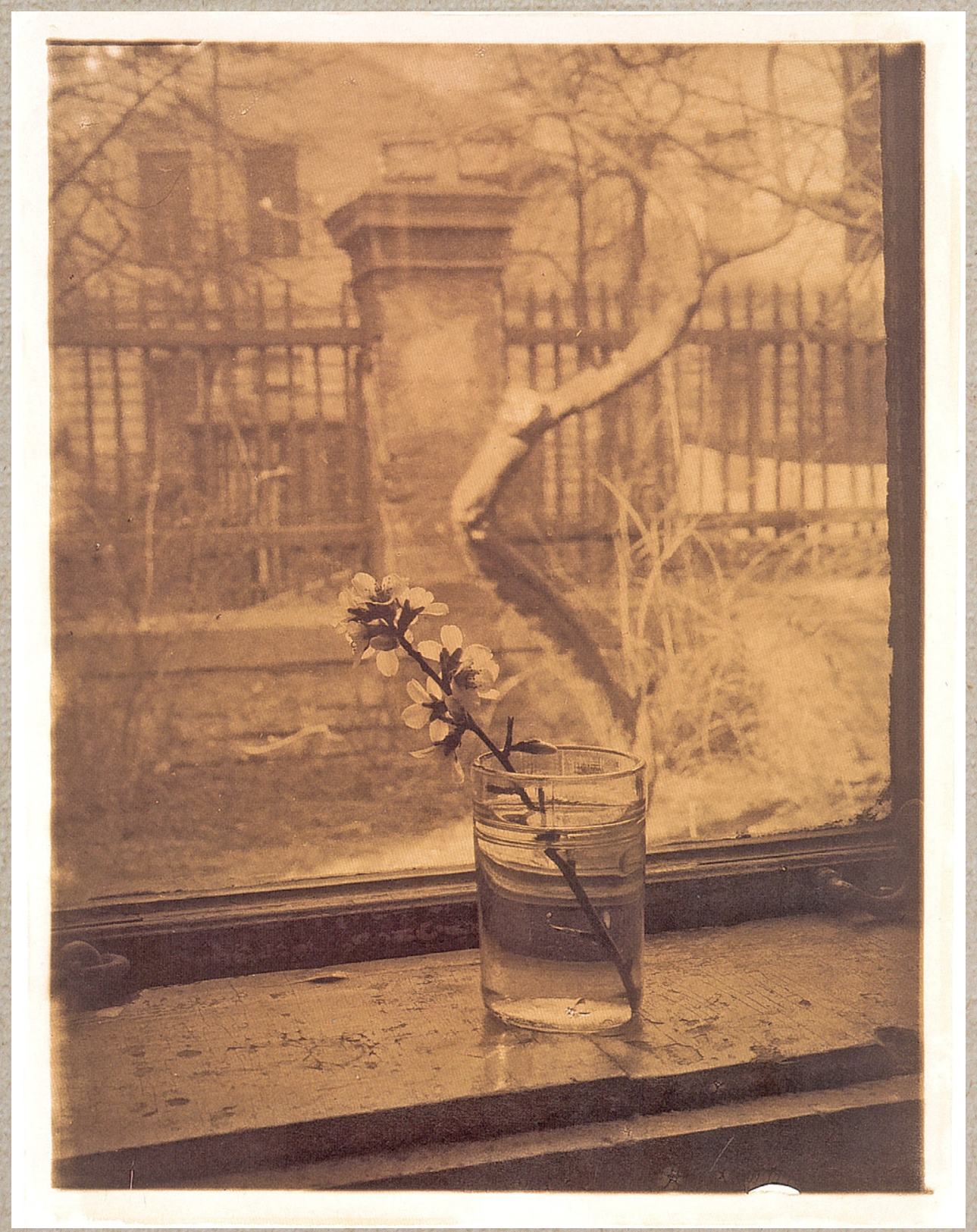

Fonte: Sudek (2001).

8 Levando-se em conta que um original fotográfico pode ser um negativo, não faz sentido apreciar o "original". 


\section{Artigos e Ensaios na atualidade: relações praticadas}

Ou ainda, no caso do artista-fotógrafo Nigel Tomm, cuja obra baseada numa ruptura com padrões fotográficos tradicionais, pode ser apreciada sem ressalvas até mesmo no seu site oficial.

Imagem 6-Arte fotográfica (2013), de Nigel Tomm.

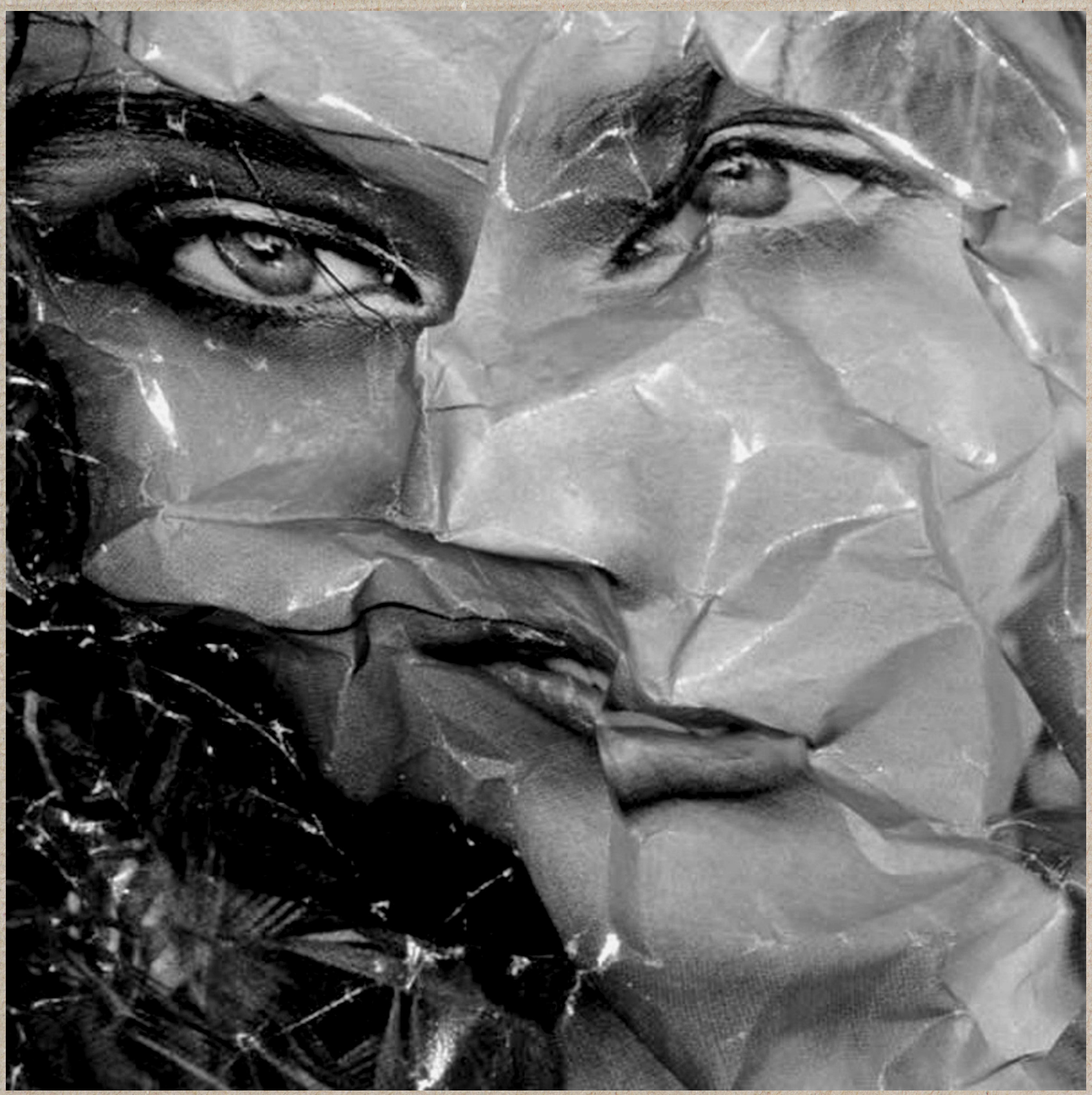

Fonte: nigeltomm.us (2018)

Onde se encontra, então, a fotografia Fine Art? Esta denominação caberia para o trabalho de Nigel Tomm? A resposta mais objetiva: depende.

Retomando as citações do encarte sobre Fine Art da revista FHOX (2013), Chiodetto menciona que Fine Art diz respeito apenas à forma como a imagem é reproduzida, ou seja, os processos 
de impressão que primam pela qualidade do produto final, enquanto que Barroso e Mascaro consideram o termo de maneira mais abrangente. Cristiano Mascaro, no mesmo encarte, afirma: "Fine Art [...] define não só a preocupação estética na criação da obra, mas principalmente seu caráter artístico, o impulso emocional e não comercial que proporcionou a decisão de se criar uma representação do mundo em que vivemos". Mas todos são unânimes numa questão: Fine Art inclui uma finalização de qualidade, própria para exibição. Seria, salvaguardadas as devidas proporções, um paralelo moderno ao que Sullivan e Weese (1998) mencionam como sendo critério de qualidade estética proceder com determinado tipo de revelação e cópia (no caso, o Platinotype) para que a imagem fotográfica adquira o status de arte. Da mesma forma, por uma questão de apresentação, a fotografia chamada Fine Art é uma imagem que se quer artística, mas numa embalagem tal que fornece uma espécie de autenticação, um crivo de qualidade que a eleva notoriamente à categoria artística.

\section{Considerações finais}

Conforme mencionado na introdução, apesar de Rouillé (2009) insistir que a fotografia deixou de ser documental e apenas recentemente foi se tornando cada vez mais expressão estética, a chamada fotografia artística tem sua gênese na própria descoberta fotográfica: Nièpce desenvolveu a Heliografia na intenção de aperfeiçoar a gravura em metal, Bayard promoveu uma exposição artística de sua técnica e Daguerre (que era pintor) igualmente começou com registros de natureza-morta. Apenas Florence, no Brasil, foi motivado por demandas comerciais, mas ainda assim fez uso estético delas. Consideraremos, portanto, para fins práticos, e, claro, em consonância com o conceito anteriormente estabelecido de arte, que a fotografia sempre se quis estética, e súa inclusão no rol de suportes potencialmente artísticos só não se deu imediatamente à sua descoberta por uma questão de embate teórico entre críticos, pelas razões acima mencionadas em relação à ilusão de sua representatividade icônica.

Hoje, o cenário que se apresenta é bastante diverso, pois a imagem digital abocanhou praticamente a totalidade da produção comercial fotográfica, deixando uma lacuna de potencial puramente expressivo, que se diluiu com a facilidade eminente dos dispositivos fotográficos em apresentar imagens em quantidades exorbitantes sem custo e sem compromisso, e que, em última análise, foi o gatilho que reacendeu a chama do trabalho fotográfico analógico, meticuloso e artesanal, numa tentativa de voltar a fazer da imagem fotográfica uma expressão relevante. David Sax (2015) explo- 
ra este tema em seu trabalho A Vingança do Analógico, em que analisa as razões pelas quais, mesmo num mundo dominado pela tecnologia digital, o suporte analógico subsiste com firmeza ao ponto de criar um rentável mercado paralelo em suas diferentes ramificações, do disco de vinil aos jogos de tabuleiro. O filme fotográfico, nesta mesma razão, encontra eco no fazer artístico não apenas por sua textura granulada naturalmente ou por.suas sutilezas cromáticas (também por isso), mas principalmente porque é um trabalho em que o fotógrafo tèm muito maior domínio do suporte, pode acompanhar todas as etapas e interferir em cada uma delas. Além disso, há também o aspecto da dificuldade de produzir uma imagem analógica, comparativamente ao digital (escolhero filme, colocar o filme na câmera, escolher a melhor exposição, foco, objetiva, esperar a revelação e a cópia, etc.) o que dá ao processo, atualmente, um estigma de comprometimento, dado o custo e o trabalho necessário. Um artigo publicado pelo The British Journal of Photography em 6 de junho de 2017, intitulado 10 More Young, Emerging \& Stablished Photographers Choosing Film, ilustra perfeitamente esta faceta, em que os fotógrafos entrevistados mostram seu trabalho em filme e explicam a razão de tais escolhas. De forma geral, as respostas foram similares, no sentido em que o trabaIho com o filme os obrigava a cuidar mais de cada etapa, trabalhar mais demoradamente e pensar melhor em cada clique. A isso corresponde o fator artístico, uma vez que estas particularidades não justificariam em si o custo de uma produção comercial em fotografia, que exige mais rapidez e os cliques bons são julgados por amostragem. Poucos trabalhos na publicidade no mundo ainda utilizam o filme, e mesmo assim por razões muito específicas.

É muito provável que venha desta sensação de 'construir' a imagem, que o filme hoje está associado, as resultantes que consideramos artísticas, às vezes de forma até exagerada, se levarmos em conta a febre da lomografia, por exemplo. Mas sem dúvida a atenção dada ao filme representa, em contrapartida à imagem insípida que o digital proporciona, uma tentativa de retornar à realização artesanal, não por mera nostalgia anacrônica, mas por uma busca à imagem de maior apuro estético, que é enormemente favorecida pelos processos analógicos, a julgar pelas informações acima mencionadas.

Em resumo: existe a fotografia, que é uma forma visual obtida através de câmera escura, e em seu interior, potencialmente, a fotografia artística - com suas intenções baseadas em ideais estéticos - e também a Fine Art, que para nossa realidade, encerra por designar um tipo de acabamento específico das cópias fotográficas que se queiram "artísticas". É preciso lembrar, contudo, que um acabamento de alta qualidade reforça, mas não cria por si mesmo uma obra de arte. Euma obra de arte também não encerra, em si mesma, a necessidade de uma roupagem específica, sem a qual pode deixar de ser arte (mas a reitera). Deste modo, entendemos que, na nomenclatura utilizada no jargão artístico brasileiro, fotografia artística e Fine Art são duas coisas distintas, que colaboram entre si e complementam-se, mas não se deve, por isso, tomar a parte pelo todo e vice-versa. 


\section{Referências}

127 FILM PHOTOGRAPHY. 2017. Blog. Disponível em: <http://127film.blogspot.com/>. Acesso em: 8 jul. 2017.

ADAMS, Ansel. The Negative. Nova York: Little, Brown \& Co., 1997.

ARNHEIM, Rudolf. Arte e Percepção Visual. São Paulo: Pioneira, 1986.

BLUR Magazine. 2016. Site. Disponível em: <https://blur-magazine.com/>. Acesso em: 18 ago 2017.

BRITISH Journal of Photography, The. 10 more young, emerging \& stablished photographers choosing film. 2017. Disponivel em: <http://www.bjp-online.com/2017/06/intrepidfilmphotographyaward_2/>. Acesso em: 15 set. 2017.

CROCE, Benedetto. Estética como ciência da expressão e linguística geral. São Paulo: É Realizações, 2016.

DUBOIS, Philippe. O ato fotográfico. Campinas: Papirus, 1993.

FERNANDES ]r., Rubens. A fotografia expandida: a produção da fotografia e o controle dos códigos de representação social na cidade do Rio de Janeiro na primeira metade do século XX. 2001. Tese (Doutorado em Comunicação e Semiótica) - Pontifícia Universidade Católica de São Paulo, São Paulo. 2002.

FLUSSER, Vilém. Filosofia da caixa preta. São Paulo: Hucitec, 1985.

FONTCUBERTA, Joan. A Câmera de Pandora. Barcelona: Gustavo Gilli, 2010.

GÉRICAULT, Théodore. A Balsa de Medusa [1818-19]. Pintura. Disponível em: <https://www.artsy.net/artwork/theodore-gericault-the-raft-of-the-medusa>. Acesso em: 15 mar. 2017.

GIRLS on Film Zine. 2011. Site. Disponível em:<https://issuu.com/girlsonfilm/docs/girlsonfilm01> [magazine]; <http://www.girlsonfilmzine.co.uk> [blog]. Acesso em: 24 out 2017.

COMBRICH, Ernst. A História da Arte. São Paulo: LTC, 2009.

HECEL, Ceorg Wilhelm Friedrich. Curso de Estética: o belo na arte. São Paulo: Martins Fontes, 2009.

HOMBAUER, Matthias; BLÜMEL, Karl. Why analog photography (still) rocks. 2013. Disponível em: $<$ https:// digital-photography-school.com/why-analog-photography-still-rocks/>. Acesso em: 10 set. 2017.

JUNG, Carl Gustav. A Energia Psíquica. Petrópolis: Vozes, 1999.

KORDIC, Angie. The relevance of analog photography today. 2015. Disponível em: <http://www.widewalls.ch/ analog-photography-collecting/>. Acesso em: 18 set. 2017

LARCE Format Photography. 1995. Blog. Disponível em: <http://www.largeformatphotography.info/>. Acesso'em: 22 set. 2017. 


\section{Artigos e Ensaios na atualidade: relações praticadas}

MACHADO, Arlindo. A Fotografia como Expressão do Conceito. Campinas: Studium, 2000.

NEWMAN, Arnold. Stravinsky Portrait. [1943]. Fotografia. Disponível em: <https://www.artsy.net/artwork/ arnold-newman-igor-stravinsky>. Acesso em: 12 dez. 2016.

Contact prints [1946]. Fotografia. Disponível em: <https://pixls.us/blog/2016/10/arnold-newman-portraits/>. Acesso em: 12 dez. 2016.

PLATÃO. A República. São Paulo: Nova Cultural, 1999.

PONOMAREV, Sergey. Refugees [2016]. Fotografia. Disponível em: <https://lens.blogs.nytimes. com/2016/04/18/photography-pulitzer-for-coverage-of-refugee-crisis/>. Acesso em: 22 set. 2017.

REVISTA FHOX. Fine Art. São Paulo, n. 162, p. 6-7, 2013.

ROUILLÉ, André. A Fotografia: entre documento e arte contemporânea. São Paulo: Senac, 2009.

SALLES, Filipe. A Ideia-imagem: forma e representação na fotografia moderna. Curitiba: Appris, 2016.

SALKELD, Richard. Comoleruma fotografia. São Paulo: Gustavo Gilli, 2014.

SAX, David. A Vingança dos Analógicos. São Paulo: Anfiteatro, 2015.

SCHILLER, Friedrich. Cartas para a educação estética da humanidade. São Paulo: EPU, 1991 a.

Teoria da Tragédia. São Paulo: EPU, 1991 b.

SOABOS Magazine. 2015. Revista Virtual. Disponível em: <https://issuu.com/soabosmagazine>. Acesso em: 5 nov. 2017.

SOUGEZ, Marie-Loup. História da Fotografia. Lisboa: Dinalivro, 2001.

SOULAGES, François. Estética da Fotografia: perda e permanência. São Paulo: Senac, 2010.

SUDEK, Josef. Pigment Prints. Salander: O'Reilly publishing, 2001.

SULLIVAN, Richard; WEESE, Carl. The new Platynum Print. Santa Fe: Working Pictures Press, 1998.

TOLSTÓI, Leon. O que é arte? Rio de Janeiro: Nova Fronteira, 2016.

TOMM, Nigel. Photography \& Art. [2013]. Fotografia. Disponível em: <http://nigeltomm.us/artphotography/>. Acesso em: 13 set. 2017.

VIEW Camera Magazine. 2010. Site. Disponível em: <http://www.viewcamera.com/index.html>. Acesso em: 8 set. 2017. 